\title{
ANÁLISE DA PROPOSTA DE ESTÁGIO NA LICENCIATURA EM \\ EDUCAÇÃO FÍSICA DA UNIVERSIDADE DE SÃO PAULO
}

\section{Marcos Garcia Neira \\ Faculdade de Educação \\ Universidade de São Paulo}

Mônica Caldas Ehrenberg

Faculdade de Educação

Universidade de São Paulo

\section{Resumo}

As mudanças atuais da Educação e da Educação Física buscam superar suas tradicionais práticas educativas para uma prática contextualizada, que amplie os significados dos alunos acerca da cultura corporal. O texto a seguir discute a experiência de estágio curricular do curso de Licenciatura em Educação Física da Universidade de São Paulo, cuja preocupação consiste no oferecimento de oportunidades para análise crítica de situações do contexto profissional docente na contemporaneidade. Evidencia-se a efetivação de uma política de estágio como processo significativo para formação de professores tendo em vista a parceria dos esforços de todas as partes envolvidas e, principalmente, situando o licenciando no interior de instituições que possibilitam o conhecimento aprofundado da realidade escolar e a experimentação prática em condições que estimulam a reflexão sobre a docência, além da visualização de alternativas para transformá-la.

Palavras-chave: Estágio; Educação Física; Licenciatura.

Olh@res, Guarulhos, v. 1, n1, p. 325-348, maio 2013. 


\title{
ANALYSING THE PROPOSAL FOR INTERNSHIP IN THE TEACHER EDUCATION COURSE IN PHYSICAL EDUCATION AT UNIVERSITY OF SAO PAULO
}

\begin{abstract}
The current changes in Education and in Physical Education aim at overcoming the traditional educational practice towards contextualized practices that broaden the meaning students assign to movement culture. The present paper discusses the experience of curricular internship in the teacher education course in physical education at University of Sao Paulo, whose main concern is to offer opportunities for critical analysis of situations from the professional teaching context in contemporary times. It's evident the implementation of an internship policy as a meaningful process for teacher education considering the partnership with all the parts involved and, above all, placing the student inside institutions that provide deep knowledge of school reality and practical experimentation that stimulate the reflection on teaching, besides the visualization of alternatives to transform it.
\end{abstract}

Key words: Internship; Physical Education; Teacher Education Courses.

Olh@res, Guarulhos, v. 1, n1, p. 325-348, maio 2013. 


\section{Introdução}

Um conjunto enorme de mudanças é facilmente observado nos campos das relações humanas, sociais, éticas, políticas, econômicas e tecnológicas. O mundo globalizado, dinâmico, veloz e cercado de modismos influi diretamente na forma como estabelecemos as relações interpessoais. Diante da intensidade com que as informações e conhecimentos são produzidos e veiculados, das exigências do mundo do trabalho e das demais atividades cotidianas, a educação formal foi obrigada a assumir novas responsabilidades.

A escola que há bem pouco tempo apresentava-se como local central para a disseminação de conhecimentos produzidos e acumulados por setores privilegiados da sociedade, neste momento se vê diante de um impasse. Tem sido chamada a assumir um novo papel, não apenas de transmissora, mas sim de promotora de reflexões acerca de tudo o que é disponibilizado pela realidade social. Para tanto, a experiência educacional deve fazer com que o aluno possa discernir se a informação disponível é válida ou inválida, correta ou incorreta, pertinente ou supérflua (ALARCÃO, 2003).

Os questionamentos também alcançaram o ensino da Educação Física. As vertentes que privilegiam a performance e o rendimento ou que se pautam num fazer desenfreado sem qualquer preocupação com os significados veiculados pelas práticas corporais não estão ajustadas à realidade e aos objetivos da educação sensível às diferenças culturais e ao ambiente democrático que caracterizam os tempos em que vivemos. Como alternativa, eclodiram propostas fundamentadas em campos teóricos politicamente comprometidos com a diminuição da desigualdade social.

As modificações não se restringem a questões didáticas. No âmbito da política educacional, é visível a quase universalização do Ensino Fundamental, a ampliação de oferta do Ensino Médio e Superior, a inclusão de pessoas com deficiências em turmas regulares, a implementação dos sistemas de ciclos de escolarização e a consolidação da autonomia da unidade escolar pela via da gestão democrática são percebidas em diversas regiões do país.

Olh@res, Guarulhos, v. 1, n1, p. 325-348, maio 2013. 
Se o modelo escolar vem sofrendo abalos, é de se esperar que o perfil dos professores também seja repensado. Revisar o currículo dos cursos que formam professores tornou-se imprescindível, tendo em vista o atendimento das novas demandas solicitadas pela realidade escolar. Ora, não é segredo que a questão da formação docente vem ocupando o centro das preocupações políticas e acadêmicas. Mesmo insuficientes, não há como negar a multiplicação das ações que visam a melhoria dos serviços prestados pelos educadores. Por outro lado, uma significativa parcela das recentes investigações sobre o tema tem denunciado os limites da formação inicial, indicando novos rumos.

Em se tratando do ensino de Educação Física, a investigação empreendida por Lippi (2005) constatou que os principais entraves para uma prática pedagógica mais eficiente se encontram, entre outros fatores, na formação dos professores. Ao entrevistar os docentes sobre suas experiências formativas, o autor descobriu que a formação inicial que acessaram distancia-se das problemáticas que se fazem presentes no momento da atuação.

Algo que já havia sido detectado por Nóvoa (1999), quando destacou o descompasso existente entre os programas de formação de professores e a realidade na educação escolar. $\mathrm{O}$ autor chama atenção para o desenvolvimento extraordinário que as ciências da educação alcançaram nas últimas décadas, ao mesmo tempo em que verifica ínfimo reflexo nas práticas pedagógicas. Em outras palavras, Nóvoa (1999) pondera que uma parte significativa dos discursos e pesquisas acadêmicas sobre o ensino não tem se materializado no ambiente escolar. Por essa razão, lança críticas ao papel das universidades no aprimoramento da formação dos professores: "a ligação da Universidade ao terreno (curiosa metáfora!) leva a que os investigadores fiquem a saber o que os professores sabem, e não conduz a que os professores fiquem a saber melhor aquilo que já sabem" (p. 15).

$\mathrm{Na}$ opinião de Tardif (2002), algumas dessas inquietações podem estar relacionadas à forma como as universidades concebem os professores:

Olh@res, Guarulhos, v. 1, n1, p. 325-348, maio 2013. 
Se assumirmos que os professores devem ser atores competentes e sujeitos ativos, deveremos admitir que a prática deles não é somente um lugar de aplicação de saberes provenientes da teoria, mas também um espaço de produção de conhecimentos específicos oriundos da mesma prática. (p. 234-235).

Ao que tudo indica, essa não parece ser a tônica dos cursos que formam professores de Educação Física. A investigação realizada por Neira (2009) sobre os currículos dos cursos de instituições públicas e privadas da cidade de São Paulo identificou uma proliferação de sentidos atribuídos ao papel do componente, polifonia de vozes com significados opostos, veiculação de informações distorcidas com relação à docência, preocupação exacerbada com a aprendizagem de conteúdos que se afastam das necessidades do profissional que atuará na Educação Básica e descaso quase absoluto pelas experiências formativas externas às aulas disciplinares.

É certo que as universidades balizam suas práticas formativas por uma concepção da profissão ligada à forma com que os cientistas e intelectuais compreendem a docência na Educação Básica. Ao tomar como base uma interpretação particular pautada por concepções de sociedade, educação, escola e área de conhecimento, as diversas atividades que compõem o currículo da formação de professores sofrerão os impactos dessa visão monológica. Em geral, quando uma instituição de Ensino Superior elabora seu projeto formativo, seleciona os elementos que considera relevantes para o exercício e os distribui em disciplinas básicas e de síntese. O contato com o mundo do trabalho propriamente dito é contemplado praticamente no final do curso.

Lima e Reali (2001) apontam que a aprendizagem da docência é um processo complexo, contínuo, marcado por oscilações e descontinuidades e não por uma série de acontecimentos lineares. Apesar disso, o que se observa é a atribuição de grande importância aos chamados "fundamentos" e um envolvimento bem menos intenso com as disciplinas responsáveis pela prática pedagógica e um tratamento marginal às experiências formativas vividas fora da universidade. Fala-se na relevância da aplicação dos conhecimentos adquiridos, mas a ausência de relação com os conteúdos disciplinares impede uma compreensão

Olh@res, Guarulhos, v. 1, n1, p. 325-348, maio 2013. 
mais profunda das ações docentes observadas ou desenvolvidas durante os estágios curriculares.

\section{O panorama atual sobre o estágio na Licenciatura em Educação Física}

O estudo de Marcon (2007) compreendeu a análise de documentos e entrevistas com os atores do estágio supervisionado. Os resultados indicam que a realização do planejamento das aulas, a possibilidade de aproximação do contexto escolar, o acompanhamento do professor-supervisor, as reflexões e os debates sobre a prática pedagógica, a inserção lenta e gradativa no mundo da docência e a descoberta da vocação para ser professor são os elementos que mais contribuem para o desenvolvimento das competências pedagógicas dos estudantes.

Aroeira (2009) analisou a contribuição do estágio para a construção de saberes pedagógicos. Realizou entrevistas com estagiários e analisou o projeto institucional e os relatórios produzidos pelos sujeitos. Evidenciou as contribuições da reflexão partilhada entre pares da universidade para a aprendizagem da docência e a importância da mediação do professorsupervisor. O estágio não é o responsável por promover a práxis de um curso de formação, mas quando partilha com a escola aspectos de colaboração e reflexão, além de pesquisa e interdisciplinaridade, pode colaborar a favor da unidade teoria-prática.

No mesmo sentido, Silva (2005) afirma que no cotidiano acadêmico é perceptível o envolvimento dos graduandos quando a universidade lhes proporciona a oportunidade de colocar conhecimentos teóricos em prática devidamente acompanhados por um supervisor, ou quando possui escolas em

permanente contato com a universidade. É necessário que o estagiário aprenda a observar e identificar os problemas, buscar informações, questionar o que encontrou, além de trocar informações com professores mais experientes. Ape-

Olh@res, Guarulhos, v. 1, n1, p. 325-348, maio 2013. 
sar do caráter otimista dos estudos mencionados, as políticas de estágio na maioria das instituições que formam professores de Educação Física deixam a desejar. Silva (2005) considera que os problemas se iniciam antes mesmo da entrada em campo, dada a proporção estagiários/supervisor incrivelmente alta, o que inviabiliza o acompanhamento in loco das atividades realizadas pelos licenciandos, como também uma discussão reflexiva dos relatórios de estágio. Sem um acompanhamento adequado, denuncia Silva (2005), o que mais se observa são documentos de estágio burlados, declarações falsas e, em casos extremos, oferta pública de serviços de falsificação de relatórios.

Já se tornou corriqueiro que a supervisão de estágios da Licenciatura em Educação Física seja encarada como um procedimento meramente burocrático, cuja ação do professor-supervisor é a cobrança e controle de entrega de cartas de credenciamento de instituições concedentes, fichas de seguro, cômputo de horas cumpridas e relatórios de estágio normalmente formatados de maneira que o aluno tenha apenas que se encarregar do preenchimento de formulários. Paradoxalmente, a impessoalidade acaba tornando-se a tônica de um processo idealizado para que o licenciando construa sua identidade profissional, onde a personalização do acompanhamento da ação e reflexão sobre a realidade vivida deveria vir em primeiro lugar. A mesma impessoalidade se estende desde a proposta da instituição formadora ao definir o como e o quê deve ser observado e escrito nos relatórios, passa pela relação entre universidade e escola e culmina nas reuniões entre professor-supervisor de estágio e licenciando.

A explicação para o fenômeno talvez resida na concepção de formação de professores dominante. É impossível negar a desvalorização pelos conhecimentos produzidos na escola, pois a instituição é vista apenas como locus da aplicação dos conhecimentos aprendidos nos bancos universitários. Quando formados, ao perceberem que a prática profissional se mostra diferente daquela apresentada nos bancos universitários, já é tarde demais. O que aprenderam durante a graduação é insuficiente para resolver os problemas que emergem cotidianamente.

Olh@res, Guarulhos, v. 1, n1, p. 325-348, maio 2013. 
Como lembra Tardif (2002),

[...] a prática profissional nunca é um espaço de aplicação dos conhecimentos universitários. Ela é, na melhor das hipóteses, um processo de filtração que os dilui e os transforma em função das exigências do trabalho; ela é, na pior das hipóteses, um muro contra o qual vêm se jogar e morrer conhecimentos universitários considerados inúteis, sem relação com a realidade do trabalho docente diário nem com os contextos concretos de exercício da função docente. (p. 257)

No caso da Educação Física, temos ainda um agravante, pois os cursos de formação de professores têm a missão de reverter uma posição que se consolidou historicamente: o predomínio de um fazer pedagógico oriundo de outros contextos que colide frontalmente com os objetivos, princípios e finalidades atuais da educação escolar. Soares (1999) atribui a permanência de práticas anacrônicas às influências que diversas instituições exteriores à escola tiveram na história da Educação Física.

Mesmo que com a publicação das Diretrizes Curriculares Nacionais de Educação Física (Resolução CNE/CES 07/2004) que regem a organização e funcionamento dos cursos de formação de professores do componente, tenham apresentado avanços bastante significativos (BENITES; SOUZA NETO; HUNGER, 2008), o que se observa é uma formação profissional repleta de lacunas, sobretudo quando os professores se deparam com a realidade escolar.

Neste sentido, torna-se relevante um trabalho de qualidade e bem articulado nos programas de formação inicial para fornecer o conjunto de conhecimentos pedagógicos que possibilitarão um enfrentamento mais qualificado dos problemas que afligem o cotidiano escolar.

\section{O Programa de Formação de Professores da USP}

$\mathrm{Na}$ busca de alternativas que revertam o atual quadro, a Universidade de São Paulo elaborou, em 2004, um novo Programa de Formação de Professores. Em síntese, trata-se de uma proposta arrojada que reconfigura o desenho curricular dos cursos de licenciatura e, entre outras mudanças, ampliou a relevância dos estágios como experiência formadora.

Olh@res, Guarulhos, v. 1, n1, p. 325-348, maio 2013. 
No âmbito da Faculdade de Educação, após um amplo debate que envolveu todos os setores da comunidade acadêmica, um novo Projeto Pedagógico das Licenciaturas (FEUSP, 2008) gradativamente substituiu o anterior formato (Bacharelado + Licenciatura).

O entendimento de que as mudanças implementadas correspondem não somente aos anseios da comunidade acadêmica, como também às necessidades formativas do futuro licenciado, levou-nos a criar e desenvolver ações que procuram integrar as discussões travadas em sala de aula às atividades de estágio nas disciplinas sob nossa responsabilidade direta (Metodologia do Ensino de Educação Física I e II), ministradas no sétimo e oitavo semestres do curso de Licenciatura em Educação Física da USP.

As representações sobre a docência que os licenciandos dos últimos semestres do curso de formação de professores de Educação Física trazem, revelam-se bastante restritas às atividades de ensino do componente. Como se os saberes necessários para o exercício profissional se limitassem aos conhecimentos dos conteúdos de ensino. O fato é comum a todas as áreas, pois, afinal, nas disciplinas cursadas anteriormente, as problemáticas que afligem o cotidiano escolar são focalizadas com as lentes dos conteúdos específicos. Essa constatação levou-nos a iniciar o estágio com atividades que aproximassem os estudantes da realidade escolar para, com o passar do tempo, aproximá-los das especificidades da docência em Educação Física.

Logo ao início do semestre, os estudantes recebem uma relação com as escolas que estão de portas abertas para realização dos estágios. A Faculdade de Educação possui convênio com algumas instituições de ensino que costumeiramente acolhem os alunos dos diversos cursos de Licenciatura da universidade. Aconselham-se a busca por essas escolas, chamadas por nós de escolas-campo, devido ao conhecimento que possuem da política de estágios da universidade. A opção pela instituição em que realizará o estágio é de inteira responsabilidade do estudante. Também é possível fazê-lo em outra escola para além daquelas apresentadas.

Olh@res, Guarulhos, v. 1, n1, p. 325-348, maio 2013. 

Educação Física I

A proposta de estágio da disciplina de Metodologia do Ensino de Educação Física I traz como eixo central o reconhecimento e apropriação do cotidiano escolar. Esta disciplina tem entre os seus objetivos proporcionar ao aluno a oportunidade de reconhecer a inserção da escola na sociedade como instituição vinculada a uma determinada comunidade; além de acompanhar aspectos do seu funcionamento que subsidiem os elementos necessários para organização de uma ação educativa alinhada ao Projeto Pedagógico da instituição.

Para atingir os objetivos da disciplina, são propostas algumas atividades de estágio: Caracterizar a escola, a comunidade escolar, os docentes e o ensino de Educação Física. Para tanto, são oferecidas diversas questões que orientam a busca de informações do estagiário. O licenciando pode consultar os arquivos da escola ou conversar com os profissionais da educação da unidade. O importante é a reunião de dados que permitam conhecer a história da instituição, como se insere na comunidade, sua organização e como é vista pelos seus frequentadores. Trata-se de uma orientação que ajuda o estudante a mapear e assim reconhecer a escola que será o seu campo de estágio.

\section{Os Roteiros:}

Na primeira atividade a proposta é de reconhecimento da escola. Como é a escola? Como a escola se vê? Como a comunidade vê a escola? Quando a escola começou a funcionar? Por que ela foi construída (iniciativa privada, pesquisa encomendada ou investigar se foi por demanda da comunidade, por decisão dos órgãos da SME/SEE etc.)? Em que local do município/bairro/região a escola foi construída (localiza-se na zona rural ou urbana, o bairro é periférico ou central)? São perguntas que compõem o roteiro de primeiro contato dos alunos.

Olh@res, Guarulhos, v. 1, n1, p. 325-348, maio 2013. 
Ainda num primeiro roteiro questões sobre a comunidade também são inseridas. Como a comunidade se vê? Como a escola vê a comunidade? Como historicamente a comunidade se formou? Há algum movimento migratório significativo? Que nome foi dado à comunidade (bairro/município) e qual seu significado histórico? Além de buscar compreender a relação existente entre a comunidade e a escola. Para isso, o caminho a nortear os estudantes aponta para investigar como a escola se relaciona com a comunidade. Como a comunidade se relaciona com a escola? Qual o nível de participação dos pais nas atividades escolares previstas no regimento interno (reunião de pais, conselho de escola, reunião de APM)? A escola desenvolve programas de integração comunidade/escola? Quais? Qual o nível de adesão da comunidade?

Após a coleta de dados, os graduandos expõem o roteiro aos colegas de forma a apresentar ao grupo a realidade escolar na qual pretendem realizar seus estágios. É um momento de socialização do mapeamento das realidades escolares transformadas em campos de estudo.

O objetivo da segunda atividade orientadora de estágio é reconhecer as funções dos diferentes atores que atuam na unidade escolar. Para cada uma das ações presentes na maioria das instituições educativas, solicitar-se-á ao estagiário que identifique o profissional da educação responsável e que descreva suas ações. Para tal, sugere-se que observe quem toma a iniciativa e quem participa de algumas ações e em seguida, descreva os procedimentos adotados pelos envolvidos.

As ações a serem priorizadas são: Organização e elaboração do Projeto Político-pedagógico; Organização e elaboração dos planos de ensino; Currículo; Resolução de conflitos na escola; Organização dos ambientes de aula; Organização dos ambientes educativos da escola; Planejamento das aulas; Planejamento dos ciclos e avaliação de desempenho da escola; Interação entre profissionais administrativos e pedagógicos; Participação das reuniões do Conselho de Escola; Reunião da equipe pedagógica para encaminhamento e objetivação das metodologias de trabalho; Decisões sobre o aproveitamento dos

Olh@res, Guarulhos, v. 1, n1, p. 325-348, maio 2013. 
alunos; Reunião de pais; Reunião de APM; Atividades extra-escolares, entre outras. Como resultado da atividade, o estagiário passa a ter uma visão ampliada da organização do trabalho na escola.

A terceira atividade aprofunda a reflexão acerca do funcionamento de alguns dos setores já mapeados. Na maioria das escolas, os sujeitos da educação se reúnem para debater questões pedagógicas com alguma periodicidade: por nível, por ano, por período de trabalho etc. Comumente, esses encontros são registrados em atas. Assim, caso seja impossível participar, o estagiário pode recorrer aos registros para coletar as informações necessárias. É possível ainda entrevistar alguns dos participantes.

Considerando os colegiados existentes na unidade - Conselho de Escola, Reunião da Associação de Pais e Mestres, Assembleia Docente, Assembleia com os familiares, Reunião Pedagógica, Conselho de Classe, Reuniões para projetos especiais, entre outras, são sugeridas algumas questões que norteiam o levantamento de dados, podendo sofrer adaptações conforme a característica do colegiado: O que se observa em relação ao conteúdo das discussões? Quem tem a palavra/conduz a reunião? Como é a composição dos membros do colegiado? Como é feita a convocação? Os grupos com menor poder participam? De que forma? A equipe técnica está presente? Qual a sua participação? Os docentes estão presentes? Como participam? Os familiares estão presentes? Como participam? Os alunos e alunas estão presentes? Como participam? A comunidade externa está presente? Como participa? Como é definida a pauta? Quem faz a ata? Quem tem direito a voto? As demandas dos diversos setores são atendidas? Entre outras questões possíveis.

Após a inserção na instituição escolar, conhecimento da sua história e relação com a comunidade, identificação das funções e responsabilidades dos profissionais da educação e funcionamento dos diversos colegiados, chegou o momento de aproximar-se das questões próprias da Educação Física.

Olh@res, Guarulhos, v. 1, n1, p. 325-348, maio 2013. 
A quarta atividade consiste no mapeamento da cultura corporal da comunidade, tendo por objetivo sensibilizar o licenciando para o patrimônio possível de ser trabalhado pedagogicamente na disciplina.

Mapear quer dizer identificar quais manifestações corporais estão disponíveis aos alunos, bem como aquelas que, mesmo não compondo suas vivências, encontram-se no entorno da escola ou no universo cultural mais amplo. Mapear também significa levantar os conhecimentos que os alunos possuem sobre uma determinada prática corporal. Não há um padrão ou roteiro obrigatório a ser seguido. Durante o mapeamento é possível recorrer a diversos instrumentos. Mas, como sugestão, solicitamos aos licenciandos que reúnam informações a partir das seguintes questões: Quais e como são realizadas as manifestações da cultura corporal? O que é produzido sobre as manifestações da cultura corporal? Como é trabalhada a cultura corporal na sua comunidade? Quem participa dessas práticas? Como são planejados os espaços para a prática das manifestações da cultura corporal?

Com o mesmo sentido solicita-se a caracterização do entorno e apontamentos acerca de quais e como são as manifestações da cultura corporal presentes no entorno da escola. Além de mapear a cultura corporal na comunidade, é fundamental que o estagiário também mapeie a Educação Física na escola. Apesar das semelhanças que possam existir entre escolas e professores, cada docente poderá significar diferentemente o papel do componente, a forma de conduzir as aulas, as temáticas abordadas, etc. Fruto das singularidades que caracterizam os sujeitos da cultura, um professor é diferente do outro e, consequentemente, o trabalho que realiza também o será. Mesmo que ele atue com turmas do mesmo ano e ciclo, o estagiário perceberá que suas práticas são peculiares. Daí ser importante conhecer o melhor possível o professor e o trabalho que realiza, sem esquecer que a análise restringiu-se a apenas um indivíduo em uma determinada realidade. Qualquer generalização das informações coletadas é veementemente desaconselhável. Para coletar os dados, recomenda-se que o estagiário tenha várias conversas com um dos res-

Olh@res, Guarulhos, v. 1, n1, p. 325-348, maio 2013. 
ponsáveis pela disciplina na escola. Sugere-se evitar o formato de entrevista com utilização de gravador ou outra forma de registro.

Como tópicos da conversa, apontamos: Há quanto tempo atua na escola? Trabalha simultaneamente em outra escola ou área? Como é composta a jornada de trabalho (horas-aula, trabalho de preparação pedagógica, estudo coletivo, estudo individual, horas-atividade, outros)? São oferecidas atividades de formação continuada? Como se dá a participação? O que pensa das atividades? Desenvolve alguma atividade extracurricular? Qual (is)? Quantas aulas de Educação Física estão previstas na grade para cada ciclo/série/ano com os quais trabalha? Qual sua carga horária semanal de trabalho com os alunos, na escola e fora da escola? Qual a relação da Educação Física com o projeto pedagógico da escola? Quais os recursos que emprega para elaboração do plano de curso? (livros, apostilas, materiais fornecidos pela instituição, PCN, Orientações Curriculares do Município, etc.). Em caso positivo, como isso ocorre? Como é a participação do/a professora de Educação Física nos colegiados? O componente se responsabiliza por algum evento da escola? Entre tantas outras questões possíveis.

No decorrer desse semestre, com os roteiros realizados, o licenciando aproximou-se da escola, conversou informalmente ou fez entrevistas com os educadores, com os demais membros da comunidade e percorreu as ruas do bairro onde se situa a instituição. Com olhar e ouvidos atentos, captou uma quantidade considerável de informações por intermédio das atividades orientadoras de estágio.

O foco agora passa a ser o relatório. O relatório de estágio é um documento que registra essa trajetória. Não se trata de uma descrição simples do tipo: "eles fazem isso, isso e aquilo" ou "a professora faz assim, assim e assim". Como se trata de um documento acadêmico, os dados precisam ser submetidos ao confronto com os conhecimentos produzidos e disponíveis. No caso em tela, as teorias que fundamentaram as discussões, filmes, textos e explicações ao longo da disciplina Metodologia do Ensino de Educação Física I.

Olh@res, Guarulhos, v. 1, n1, p. 325-348, maio 2013. 
Em suma, os dados coletados por si só dizem muito, mas só isso não basta. Precisam ser interpretados a partir das teorias. Advém daí a necessidade de fundamentar-se para, posteriormente, debruçar-se sobre o material recolhido. Isso significa que a formatação do documento escrito a ser entregue assemelhase a um relatório de pesquisa.

\section{A experiência formativa de estágio da disciplina Metodologia do Ensino de Educação Física II}

Principalmente no que diz respeito ao estágio, é absolutamente fundamental que o licenciando permaneça na mesma instituição que frequentou durante as atividades solicitadas na disciplina Metodologia do Ensino de Educação Física I.

Desta vez, a Metodologia do Ensino de Educação Física II visa apresentar conhecimentos teóricos e práticos que possibilite um desempenho crítico da função docente. A disciplina busca ainda proporcionar ao licenciando a oportunidade de intervir no processo educativo da Educação Física em uma instituição escolar, além de acompanhar e colaborar em todas as etapas do trabalho docente: elaboração do plano de ensino (construção de objetivos e seleção de conteúdos de ensino), execução, avaliação contínua e avaliação final.

\section{Desenvolvimento de um projeto de ensino}

Como se trata de um trabalho em parceria com o professor responsável pela turma, é importante que o estagiário elabore um projeto de intervenção coerente com o plano já existente. As informações coletadas mediante as atividades orientadoras realizadas no semestre anterior devem ser utilizadas para retroalimentar a proposta de ensino da escola e, consequentemente nutrir o programa que será experimentado. O tema escolhido, as características das atividades de ensino, os recursos utilizados, o tempo de duração, os instrumentos de avaliação e todas as questões que envolvem o projeto didático variam conforme as representações do licenciando, do professor da escola, a

Olh@res, Guarulhos, v. 1, n1, p. 325-348, maio 2013. 
cultura institucional e as especificidades da turma de alunos. O papel do professor supervisor nesse momento é simplesmente ajudar o universitário na elaboração do seu plano de trabalho e nas estratégias que possa utilizar, sobretudo, se for municiado de informações acerca do andamento das atividades. Uma vez encerradas as atividades, solicita-se ao estagiário a entrega de um relato de experiência.

Denominamos de "Relato de experiência" o registro das atividades de ensino realizadas no decorrer de um determinado período letivo. O texto final deve externar as intenções educativas, os procedimentos adotados no desenvolvimento das atividades e as reflexões sobre os efeitos do processo nos alunos. Os resultados que se julga ter alcançado, o formato das avaliações, o retorno a uma atividade ou outra para retomar algum ponto importante que possa ter sido menos evidenciado precisam ser explicitados. Isso é particularmente relevante, pois propiciará material para análise e descoberta de alternativas tanto para o autor, que avalia sua prática enquanto elabora o registro, quanto para um eventual leitor, que poderá tomar para si as reflexões elaboradas.

O relato de experiência documenta uma determinada trajetória pedagógica. Consequentemente são fundamentais informações sobre a articulação com o projeto pedagógico da instituição, quem foram os atores envolvidos, quais conhecimentos foram mobilizados, os procedimentos adotados e, principalmente, as modificações identificadas nas representações dos participantes. Ou seja, o registro da prática é uma forma eficaz para analisar o trabalho educacional e seus reflexos na constituição dos sujeitos da educação.

Trata-se de uma oportunidade preciosa para socializar as reflexões e compartilhar o que em sua opinião podem ser vistos como pontos positivos e negativos.

Relatar uma experiência não é o mesmo que narrar ações bem sucedidas. É bom ressaltar que se aprende muito com aquelas atividades e procedimentos que não transcorreram conforme o esperado ou que não alcançaram os objetivos pro-

Olh@res, Guarulhos, v. 1, n1, p. 325-348, maio 2013. 
postos. Dando visibilidade aos equívocos e deslizes, outros aprenderão e, quem sabe, precavidos, possam contornar os problemas antes mesmo do seu surgimento. Frise-se que o professor supervisor é o seu principal interlocutor, mas nada impede que sua narrativa seja lida por seus colegas de curso, professores da escola que estagiou ou de outras escolas. Por meio do relato é possível apresentar práticas, intercambiar pontos de vista, apresentar intenções e analisar incômodos do cotidiano pedagógico. O diálogo travado com quem vive problemas semelhantes consiste em apoio interessante no momento de planejar as ações didáticas. Decidir sobre as atividades, enfoques e estratégias futuras e, ao mesmo tempo, questionar o que se vem fazendo, poderá levar à aprendizagem com a própria experiência e, melhor que isso, desfrutar de uma maneira diferente de aprender e ensinar.

Analisar as ações educativas desenvolvidas não deixa de ser uma alternativa para a formação, além de semear mudanças no ambiente educacional. Afinal, o relato de experiência poderá fomentar a revisão de conceitos e práticas fossilizadas, o que sem dúvida subsidiará a construção de novos conhecimentos pedagógicos.

O relato de experiência difere radicalmente do "faça como eu faço" ou das "boas práticas". Ele se fundamenta justamente na tentativa de compreender o que levou o seu autor a tomar determinadas decisões e como elas refletiram nos alunos. Como ninguém aprende nada sozinho, compreender como o colega significou um dado percurso, atividade ou situação enfrentada, pode ser mais apropriado do que uma ação pedagógica solitária e baseada na tentativa e erro.

\section{Análise dos relatórios}

Sodré (2011) analisou os relatórios de estágio e os relatos de experiência de todos os concluintes do curso de Licenciatura em Educação Física da USP em 2009 e 2010. Seu estudo evidencia aspectos positivos e negativos com relação à proposta acima descrita. Dentre as questões que precisam ser revistas, destaca a

Olh@res, Guarulhos, v. 1, n1, p. 325-348, maio 2013. 
integração entre os envolvidos no processo do estágio. Os alunos se queixam da falta de uma participação mais ativa dos professores das escolas. Ressentem-se da ausência de envolvimento, principalmente, no momento de planejar as intervenções: "o professor era desanimado", "o professor estava cansado", "o professor não fazia questão de discutir", relatam os autores. A maior parte das suas análises coincide com as nossas.

Quem fez estágio em escola privada observou os preconceitos que a Educação Física enfrenta, normalmente ficando à parte das reuniões e discussões de caráter pedagógico. Dentre os apontamentos registrados pelos estagiários encontramos: "nunca acontece uma reunião dos professores de Educação Física com os demais professores, por acharem que as disciplinas são muito diferentes e que não há correlação entre elas", ou "os professores são isolados e não trocam experiências sobre o que ensinam e até mesmo sobre o aprendizado e comportamento dos alunos, esquecem que a reflexão e o intercâmbio de informações podem construir novas formas de atuação e relacionamento entre professores, alunos e até mesmo com a direção da escola".

Percebemos o estabelecimento de um sistema hierárquico rígido e bem definido no contexto da educação privada. Porém, há o relato de uma experiência em escola pública afirmando que nesta é "mais fácil acessar níveis hierárquicos maiores, como a direção".

No entanto, o preconceito em relação ao professor de Educação Física não é menor na escola pública, onde muitas vezes, de acordo com as afirmações dos estagiários, "a Educação Física é considerada aula vaga", "é uma disciplina que não reprova" e ainda usada como moeda de troca: "se os alunos não se comportarem não tem Educação Física".

A realidade escolar é bem diferente da teoria que se conhece a respeito da atuação do professor de Educação Física. Os apontamentos nesse sentido vão desde questões mais burocráticas até elementos do cotidiano. Alguns estagiários ficaram surpresos com o fato de o professor ou a escola não seguirem uma abordagem específica: “o professor não sabia a abordagem que

Olh@res, Guarulhos, v. 1, n1, p. 325-348, maio 2013. 
estava trabalhando" ou então "parece ser difícil seguir uma linha só". Tal surpresa também ocorria quando tinham a oportunidade de ler algum documento relacionado à abordagem da disciplina na escola ou mesmo Projeto Pedagógico: "a documentação trata a área corporal com maior importância do que é dado na prática”.

O trabalho cotidiano no que tange à resolução de conflitos e a mediação das relações parecem ser a maior preocupação dos estudantes: "achei difícil controlar a turma e dividir os grupos", "a indisciplina é um dos maiores problemas na escola"; soma-se a isso as questões que envolvem as relações de gênero nas aulas: "meninos dominam as meninas nas aulas", "meninos fazem e meninas assistem", "meninas só fazem aula se tiver vôlei ou handebol”.

Para muitos estudantes, o estágio é o momento de conhecer a realidade da sua profissão e, para esse objetivo, mostra-se eficaz, como visto em relatos como este: "o estágio é importante para entrar em contato com a realidade", "este estágio contribuiu de forma significativa para minha formação, pois possibilitou uma aproximação com a realidade escolar...”. Há ainda aqueles que dizem: "aprendi como não dar aula de Educação Física" ou "aprendi o que não aprendi na faculdade", reforçando a visão do estágio como instrumento de união entre a teoria aprendida na graduação e os conhecimentos práticos adquiridos somente em situações reais de trabalho.

Alguns relatórios analisados neste trabalho, entretanto, eram simplesmente descritivos e se prendiam somente às características físicas da escola e do seu entorno, não apresentando reflexões, críticas ou mesmo manifestações de contentamento (ou descontentamento) com a atividade. Esse fato deixou a impressão de que seus autores estavam somente cumprindo o estágio como mais uma tarefa exigida pela academia.

A compilação e interpretação do material permitem concluir que os posicionamentos negativos emitidos pelos estagiários se referem à situação da escola contemporânea como um todo, na qual, muitas vezes, a indisciplina é

Olh@res, Guarulhos, v. 1, n1, p. 325-348, maio 2013. 
uma situação corriqueira, dentre outros "problemas" relacionados à Educação no geral e à Educação Física no particular.

Assim como Sodré (2011), observamos que o estágio teve um papel fundamental na formação desses estudantes por ter-lhes proporcionado a possibilidade de, a partir da experiência, construir um senso crítico a respeito da área de conhecimento e intervenção da qual farão parte, não mais como estudantes (aprendizes), mas como profissionais. Assim, mesmo quando os estagiários usam em seus relatos termos como "aula vaga" ou "difícil de aplicar os conteúdos", percebemos uma preocupação com o empreendimento eficaz do seu conhecimento teórico, porém vê-se claramente que na prática, muitas dificuldades emergem.

\section{Considerações finais}

O saldo interpretativo que atingimos demonstra que os estagiários vão para a escola e encontram uma realidade infinitamente diferente da que veem na universidade e que acessam por meio das leituras e discussões do curso de Licenciatura. Isso, de forma alguma diminui o valor da vivência do estágio, pelo contrário, como já dito acima, proporciona um momento de reflexão e a formação de uma opinião crítica a respeito da situação do contexto profissional do professor de Educação Física na contemporaneidade.

Quando confrontamos as informações atingidas pela análise com as ideias e argumentos presentes na produção científica sobre o tema, verificamos que há uma tendência de pensamento que converge para uma nova estrutura de estágio que favoreça a construção de uma prática docente de qualidade. Parece ser consenso que o estágio de qualidade seja aquele que proporcione ao estudante a ressignificação das práticas docentes, por meio de trocas com os colegas no espaço universitário ou com os professores em atuação no ambiente escolar, socializando e produzindo conhecimentos.

Olh@res, Guarulhos, v. 1, n1, p. 325-348, maio 2013. 
Podemos dizer então que o estágio torna-se, assim, muito mais significativo no processo de formação dos alunos quando se envidam esforços de todas as partes envolvidas (alunos, professores supervisores, professores das escolas, escolascampo e universidade) e, principalmente, quando permite ao aluno a experimentação prática em condições adequadas para que possa refletir a respeito dela e, ao mesmo tempo, transformá-la.

O que norteou esta análise foi identificar as contribuições das experiências de estágio para a formação dos professores de Educação Física da USP. O resultado do levantamento das leituras dos relatórios mostrou que esse processo de formação não é simples. A observação efetuada nos estágios leva o observador a elaborar críticas e reflexões a respeito da atuação do professor, porém verificamos que no momento em que o estagiário assume o papel do professor (regência), tais críticas não se refletem em sua prática como aparecera em seu discurso.

No momento de atuar como professor, as maiores preocupações dos estagiários, registradas nos relatos, dizem respeito às questões cotidianas da aula, como mediação de conflitos, manutenção da ordem, etc. Ficando para o segundo plano as questões relacionadas a quem os alunos estão se tornando, aos objetivos da ação didática, ao que seus alunos estão aprendendo (conteúdos) e como estão aprendendo (metodologia), ou seja, a tarefa pedagógica stricto sensu. Tal conjuntura pode ser um indicativo da necessidade de mais horas de estágio prático (regência), além da observação. Evidencia-se também a distância entre a formação inicial dos futuros professores e a realidade na qual serão inseridos no decorrer de sua trajetória profissional.

Tal fato é criticado por Betti e Galvão (2001). As autoras enfatizam que a prática escolar mais tradicional, qual seja o ensino a partir dos currículos, faz com que o aluno (futuro professor) apresente certa insegurança no início da profissão, pois a experiência não parece ser suficiente para fornecer segurança na formação pedagógica do estudante. Ainda complementam afirmando que o aluno precisa ser inserido na prática, o mais cedo possível, para que possa

Olh@res, Guarulhos, v. 1, n1, p. 325-348, maio 2013. 
construir novas ações, estratégias, fórmulas de pesquisa, modos de enfrentar e definir problemas, possibilitando experiências e evitando pressões que a prática carrega.

Superar algumas das dificuldades da relação teoria-prática é uma grande contribuição do estágio na formação do estudante de Educação Física e deve ser, cada vez mais, eficiente em seu objetivo. A inserção do futuro professor no contexto escolar durante a graduação é interessante, pois o quanto antes este entrar em contato com sua realidade profissional mais situações e mais oportunidades de práticas docentes poderão ser experimentadas e, a partir daí, discutidas e refletidas na universidade com o respaldo dos tutores e professores da escola, ambos responsáveis pela gestão dessa vivência. O espaço para as discussões e troca de experiências também deve ser mais valorizado.

Com a revisão da literatura e com a leitura e análise dos relatórios foi possível verificar diferentes olhares a respeito da contribuição do estágio na formação do futuro professor de Educação Física. Com base nisso, acreditamos que o estágio deve transcender os limites burocráticos da Licenciatura e propiciar a compreensão real acerca da atuação profissional do professor. O estágio é a porta de entrada do futuro profissional em seu ambiente de trabalho, logo sua importância é inegável.

Olh@res, Guarulhos, v. 1, n1, p. 325-348, maio 2013. 


\section{Referências Bibliográficas}

ALARCÃO, I. Professores reflexivos em escola reflexiva. São Paulo: Editora Cortez, 2003. AROEIRA, K. P. O estágio como prática dialética e colaborativa: a produção de saberes por futuros professores. 2009. 184f. Tese (Doutorado em Educação). Faculdade de Educação. Universidade de São Paulo. São Paulo: FEUSP, 2009.

BENITES, L. C.; SOUZA NETO, S.; HUNGER, D. O processo de constituição histórica das diretrizes curriculares na formação de professores de Educação Física. Educação e Pesquisa, São Paulo, v.34, n.2, p. 343-360, maio/ago. 2008.

FACULDADE DE EDUCAÇÃO DA USP. Projeto Pedagógico das Licenciaturas. São Paulo: FEUSP, 2008.

LIMA, S. M. de, REALI, A. M. de M. R. O papel da formação básica na aprendizagem profissional da docência (Aprende-se a ensinar no curso de formação básica). In: MIZUKAMI, Maria G. N., REALI, Aline M. de M. R. (orgs.). Formação de professores, práticas pedagógicas e escola. São Carlos: EdUFSCar, 2002, p.217-235.

LIPPI. B. G. Educação Física no Estado de São Paulo: a visão do professor. Presidente Prudente: UNESP, 2005. (Relatório de Pesquisa).

MARCON, D. A construção das competências pedagógicas através da prática como componente curricular na formação inicial em educação física. Revista Brasileira de Educação Física e Esporte. São Paulo, v. 21, n.1, p 11-25, jan./mar. 2007.

MOURA, F. B.; SILVA, L. F. P. Percepção de ingressantes e de egressos de um curso de educação física a respeito de prováveis áreas de atuação. (Monografia). Bacharelado em Educação Física. Universidade São Judas Tadeu, São Paulo, 2004.

NEIRA, M. G. Desvelando Frankensteins: interpretações dos currículos de Licenciatura em Educação Física. Revista Brasileira de docência, ensino e pesquisa em Educação Física, Cristalina, v.1., n. 1, p. 118-140, ago. 2009.

NÓVOA, A. Os professores na virada do milênio: do excesso dos discursos à pobreza das práticas. IN: Educação e Pesquisa. São Paulo, v.25, n.1, p. 11-20, jan/jun,1999.

TARDIF, M. Saberes docentes e formação profissional. Petrópolis: Vozes, 2002.

Olh@res, Guarulhos, v. 1, n1, p. 325-348, maio 2013. 
UniVersidade De SÃo PAUlo. Programa de Formação de Professores. São Paulo: USP/PRG, 2004.

SILVA, S. A. P. S. Estágios curriculares na formação de professores de educação física: o ideal, o real e o possível. Lecturas Educación Física y Deportes, Buenos Aires, año 10, nº 82, Marzo 2005. Disponível em <http://www.efdportes.com/efd 82/estagios.htm> acesso em 30/08/2010.

SODRÉ, M. L. A Formação de professores de Educação Física na Universidade de São Paulo: análise das experiências de estágio disciplinar. São Paulo: FEUSP, 2011. (Relatório de Pesquisa).

Olh@res, Guarulhos, v. 1, n1, p. 325-348, maio 2013. 